\title{
A Hermenêutica filosófica como práxis
}

\author{
RODRIGO VIANA PASSOS *
}

RESUMO A hermenêutica filosófica de Gadamer se funda no horizonte ontológico e histórico da compreensão. Porém, uma das contribuições mais importantes trazidas por suas reflexões em Verdade e Método é a correlação entre a hermenêutica e a filosofia prática aristotélica, repensando dois conceitos-chave: práxis e phronesis. Influenciado pelas intelecções de Heidegger sobre o estagirita, encontra no livro VI da Ética a Nicômaco uma luz para o caráter fundamental do pensar e do agir humanos como sabedoria prática, que implicaria na forma como se compreende o mundo circundante. No que Aristóteles chamaria de conhecimento de si mesmo para o agir ético visando o bem comum, Gadamer encontrará o sentido para a autocompreensão, que é um dos momentos necessários para qualquer “atividade” hermenêutica. É a dimensão ético-política o seio mais próprio de racionalidade do homem. Acreditamos que com isso Gadamer pretende resgatar o papel da razão prática em detrimento de uma que se constitua de maneira puramente lógica e formal, desvinculada do mundo da vida em comum e de suas exigências sempre novas. Com efeito, o ser-aí (Dasein) sempre se vê antecipado por um mundo linguisticamente interpretado e legado na história. É a partir dessa tradição que o humano se posiciona compreensivamente frente às coisas, mas na medida em que as coisas mesmas pedem de sua práxis um agir compatível com suas exigências concretas. Pensar a hermenêutica nesses termos é realçar que o ser humano é inafastavelmente com os outros em suas atividades mais constitutivas. Não é apenas dizer que o mundo humano, com todas as suas produções culturais é ético e histórico, mas também que o próprio compreender é práxis histórica realizadora e atualizadora de sentido. Ocupar-nos-emos, portanto, de explicitar de que maneira

* Pontifícia Universidade Católica do Rio de Janeiro Mestrando pelo Programa de Pós-Graduação em Filosofia Bolsista CAPES Gadamer reabilita a filosofia prática aristotélica para que ela exerça um papel central no interior de sua hermenêutica filosófica, afastando-a de um horizonte meramente metodológico.

Palavras-chave Gadamer; Aristóteles; Hermenêutica; Práxis 


\section{INTRODUÇÃO}

Iniciamos este trabalho com uma advertência-princípio: a hermenêutica filosófica gadameriana não é um método, mas fenomenologia da compreensão enquanto tal. Portanto, não pretende advogar regras para uma correta interpretação de textos e/ou discursos orais, mas “simplesmente” - o que quer dizer, em verdade, complexamente - refletir filosoficamente acerca do modo de ser da nossa relação compreensiva com as coisas e os outros. Gadamer, nesse sentido, nos diz que “[m]inha real preocupação era e é filosófica: não o que nós fazemos ou o que devemos fazer, mas o que nos acontece acima e para além de nosso querer e fazer"

Noutro giro, também não numa perspectiva apriorística, mas a partir da própria concretude de nossos afazeres no mundo comum, que é linguística e tradicionalmente legado - podemos dizer, como Aristóteles, daquilo que nos é mais conhecido, familiar -, implicando uma série de enredamentos pelas mais variadas experiências típicas do humano: o estar com os outros, o falar, o escrever, a arte, a história, o concretizar esperanças e lidar com estranhamentos. Tendo isso em mente, fica-nos latente a tarefa de pensar a hermenêutica filosófica como o rigor próprio subjacente a todas as instâncias da vida humana, as quais, nesse sentido, encontram-se necessariamente enredadas num horizonte eminentemente prático de nosso viver em geral².

Nesse sentido, entendemos que é oportuno e central para essa discussão a reabilitação da filosofia prática aristotélica por Gadamer no seio de Verdade e Método (1960), pois acreditamos que ela contribui para fortalecer a universalidade da hermenêutica em sentido ontológico e não apenas formal (como seria o caso se ela fosse uma metodologia). Ao refletir sobre o agir humano enquanto práxis, a partir da leitura da Ética a Nicômaco, Gadamer identificará uma “estrutura” básica para o todo da vida do

1 GADAMER, 1996, p. xxvii. Utilizaremos a tradução americana de Wahrheit und Methode feita por Joel Weisheimer e Donald G. Marshall como base, trazendo no corpo do texto uma tradução livre nossa a partir de ambos os textos (alemão e inglês), sem descurar das traduções brasileira (F.P. Meurer) e espanhola (A. A. Aparicio e Rafael de Agapito).

2 Cf. DUQUE ESTRADA, 1993; e BATISTA, 2007. Tais textos foram fundamentais para se ter uma real noção da dimensão do problema da filosofia prática na hermenêutica filosófica gadameriana. 
homem enquanto ser que age a partir de um todo comum e com vistas a esse mesmo todo e a partir de situações concretas sempre e sempre novas.

Assim, o próprio reabilitar filosoficamente se insere na dinâmica própria da hermenêutica filosófica, na medida em que não se trata simplesmente de uma reprodução do pensamento aristotélico, mas sim sua aplicação a novos desafios do pensar e fazer humanos da contemporaneidade.

Por fim, devemos adiantar que a presente investigação se insere num contexto mais amplo de pesquisa sobre as origens do pensamento gadameriano. Sabemos que Gadamer foi um voraz leitor e intérprete de amplo espectro do pensamento filosófico, mas que existem, obviamente, marcos capitais em sua trajetória, sendo um deles o seu estudo e reflexão sobre a filosofia antiga, em especial Platão e Aristóteles. Com efeito, se já não bastasse o fato de que no seio de suas Gesammelte Werke (Obras Completas) existirem três volumes destinados exclusivamente ao estudo da filosofia grega, temos reiteradas aparições de temas e conceitos platônicos e aristotélicos como fios condutores de suas discussões (tanto escritas quanto em debates em conferências etc.). Mais especificamente, pretendemos ao longo de tal pesquisa compreender uma tarefa que Gadamer parece ter se imposto e como ela teria se materializado em Verdade e Método, a saber: demonstrar a "unidade" do pensamento platônico e aristotélico no que diz respeito a uma filosofia do logos. Ainda não atingimos nem de longe a completa intelecção e solução de tal problema, mas, de qualquer modo, este trabalho seminal se insere em tal caminho.

\section{DE HEIDEGGER A GADAMER: BREVES CONSIDERAÇõES E DIFICULDADES}

Não é o propósito aqui enveredar por essa difícil e controversa temática da relação entre Heidegger e Gadamer. Há muita coisa em jogo para se pretender resolvê-la com algumas poucas palavras. Desse modo, o que se tentará apontar aqui sobre tal questão deve ser somente isso: um apontamento, algo que indique uma possível via de acesso ao que gostaríamos de tratar aqui propriamente. Serão, portanto, indicações gerais de caminhos do pensamento heideggeriano que o próprio Gadamer afirma ter tomado para seu pensamento; caminhos estes que têm em Aristóteles um sentido fundamental. Para tanto, teremos em vista somente “obras” pré-Ser e Tempo. 
É público e notório que Heidegger é uma figura central e constante nos escritos de Gadamer, a tal ponto que o pensamento deste é muitas vezes tomado como simplesmente uma faceta ou continuação daquele. Pode-se tomar isso positivamente ou como uma ofensa, isso não vem ao caso. O fato é que ele está lá com seu olhar vigilante.

Com efeito, como nos é dito em Lembranças dos momentos iniciais de Heidegger ${ }^{3}$, foi a partir da leitura de um texto sobre Aristóteles, que Heidegger havia escrito e enviado para Paul Natorp - o qual por sua vez o emprestou para a leitura -, que Gadamer imediatamente fora desperto para novas dimensões interpretativas sobre o estagirita ${ }^{4}$ - e daí em diante sobre os gregos em geral -, levando-o inclusive a distanciar-se progressivamente do neo-kantismo ainda forte à época. A partir daí temos um Gadamer assíduo nos preleções e leituras heideggerianas. Dentre elas, iremos destacar três, as quais dizem muito do interesse gadameriano pela filosofia prática aristotélica: Phänomenologische Interpretation zu Aristóteles (Interpretações fenomenológicas sobre Aristóteles, semestre de inverno de 1921/22); Ontologie (Hermeneutik der Faktizität) (Ontologia: Hermenêutica da facticidade, semestre de verão de 1923); Grundbegriffe der aristotelischen Philosophie (Conceitos fundamentais da filosofia aristotélica, semestre de verão de 1924).

Permitindo-nos uma avaliação sumária - e até certo ponto bastante apressada -, o que se delineia como um "gesto" de pensamento comum nessas preleções é a busca de um arcabouço conceitual que dê conta de uma reflexão fática sobre o modo de ser do "homem", ou, melhor dizendo, do ser-aí (Dasein), e, mais originariamente, uma caracterização de algo como um estar desperto para o mundo a partir dessa própria efetividade do modo de ser do homem. Gadamer se reporta a isso como o laborioso esforço do ser-aí em clarificar-se, ser si mesmo, “estar desperto junto ao fogo da

3 GADAMER, 2007, p. 9-24

4 “O que foi importante para mim, em particular para a minha inserção em Aristóteles, foi precisamente o fato de Heidegger ter conseguido fazer com que eu compreendesse claramente que Aristóteles não era o ‘realista’ ante o ‘idealista’ Platão. [...] Do mesmo modo fascinou-me a introdução heideggeriana à ética aristotélica. Aqui, ele colocou em jogo todo o pathos de sua Hermenêutica da Facticidade em favor da interpretação de Aristóteles. Hermenêutica da facticidade, é justamente isso que também aprendemos a partir da recentíssima publicação da preleção de 1921/1922, significa uma interpretação do ser-aí humano que segue a auto-interpretação desse ser-aí na concreção de seu mundo da vida. Para tanto, a ética aristotélica podia de fato servir em certo sentido como um equivalente" (GADAMER, 2007, p. 14, Lembranças dos momentos iniciais de Heidegger) 
noite"5. É bastante eloquente o fato de que que a preleção Conceitos fundamentais da filosofia aristotélica siga um itinerário que parte da caracterização do ser-aí em seu modo prático e comunitário (no falar sobre as coisas, ser capaz de lógos). De fato, Heidegger nos diz que:

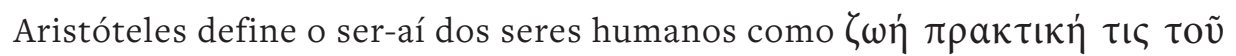

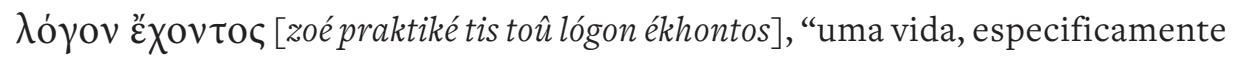

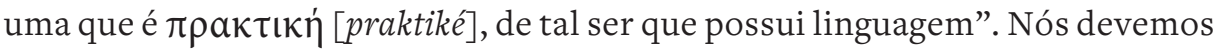
levar a cabo uma interpretação dessa definição para que procuremos uma visão concreta daquilo que Aristóteles entende por ser e ser-aí dos seres humanos.

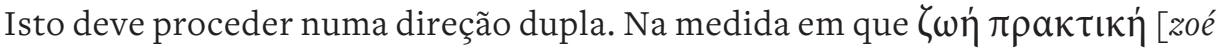

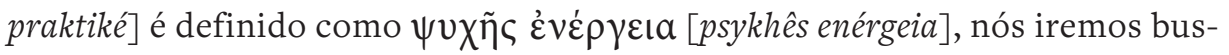
car o sentido e o contexto concreto que é significado por ẻvé $\rho \gamma \varepsilon\llcorner\alpha$ [enérgeia] assim como o contexto que é significado com $\psi v \chi \tilde{\eta} \varsigma[p s y k h e ̂ s]^{6}$.

A partir daí, o ser-aí será caracterizado por sua constante busca por “obrar-se”, ou seja, ser uma constante enérgeia ("trabalho") de si mesmo em vistas de um épjov (érgon, obra). O trabalho do ser-aí se dá por um constante questionar sobre seu ser, seu télos, segundo Heidegger, o seu destino frente ao mundo - que em Aristóteles seria a

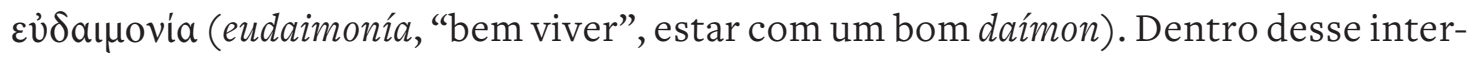
minável caminhar do ser-aí na busca por si mesmo, “Aristóteles busca possibilidades básicas dentro dessa possibilidade concreta do ser-aí, de acordo com as quais todo ser-aí concreto decide sobre si mesmo"7, sendo uma delas a “existência” (Existenz), a qual Heidegger articular com a vida contemplativa ou teórica dos gregos.

Por fim, a preleção do verão de 1923 é com poucas dúvidas uma das mais significativas para Gadamer em seus desdobramentos até Verdade e Método. O curioso é que, se o primeiro tema (da hermenêutica) parece progressivamente perder importância para Heidegger - principalmente pós Ser e Tempo -, assim como o peso de Aristóteles ${ }^{8}$, Gadamer os reabilitará como temas caros a si mesmo: compreensão e mundo prático-

5 GADAMER, 2007, p. 67. Essas teriam sido palavras de Heidegger, ditas em uma reunião de final de semestre em sua cabana na Floresta Negra, a que Gadamer se reporta de memória.

6 HEIDEGGER, 2009, p. 31. Tradução minha a partir da tradução americana de R.D. Metcalf e Mark B. Tanzer e do original alemão.

7 Idem, p. 31.

8 Cf. VOLPI, 2013. Tal obra oferece um bom panorama da presença do pensamento aristotélico na obra de Heidegger. 
-efetivo. Se as preleções anteriores já traziam significativo material fenomenológico sobre Aristóteles, Ontologia (Hermenêutica da facticidade) o articulará com o problema da hermenêutica. Ambas as temáticas se implicarão mutuamente, ganhando para Gadamer outro âmbito de atuação filosófica, entrando em jogo, por exemplo, problemas como o da história e historicidade. O ser-aí é um ente que compreende a si mesmo em seu ser, e esta compreensão mesma o define a cada momento historicamente ${ }^{9}$.

É verdade que a orientação do questionamento heideggeriano tem um alvo distinto do gadameriano, na medida em que quer, a partir desse modo de ser hermenêutico do ser-aí, ter um acesso mais originário sobre ele, ou seja, lá onde ele pergunta tematicamente pelo seu ser - faz ontologia em sentido "forte". Por seu lado, Gadamer parece já ter isso como pressuposto de suas investigações, e deseja expandir as consequências disso para o próprio modo como o ser-aí compreende os outros linguisticamente. De qualquer modo, acreditamos que restam delineados alguns pontos centrais desse diálogo Heidegger-Gadamer e que nos possibilitam ter mais clareza nessa recepção de Aristóteles por Gadamer.

\section{HERMENÊUTICA E COMUNIDADE}

Devemos reconhecer que Verdade e Método é de difícil entendimento tanto por sua erudição, quanto por sua estrutura argumentativa, seleção e articulação de temas da história da filosofia. Pode parecer, por exemplo, que uma parte do primeiro capítulo poderia ser simplesmente descartada. Seria o caso em especial de "Os conceitos básicos do humanismo". Porém, quem considera tal possibilidade parece perder de vista algumas questões fundamentais que se mimetizam ao longo de todo o livro. Poderíamos resumi-las no seguinte: o modo de ser do humano como eminentemente ético e comunitário em oposição ao subjetivismo moderno, que fundamenta as ciências naturais da modernidade e influencia a própria autocompreensão das ciências do espírito. Nesse sentido, com o passar da leitura, percebe-se que a hermenêutica filosófica se caracteriza justamente por defender o compreender como estrutura básica da vida humana, e que ele está necessária e previamente ancorado e se efetiva numa totalidade comunitária legada pela tradição.

9 cf. HEIDEGGER, 2013, p. 13-14. 
O que são, nesse contexto, as obras de arte e como se dá nossa relação com elas? O segundo capítulo se presta justamente a responder tal questão deslocando a postura estético-subjetivista da modernidade para uma ontológica fundada numa alteridade básica, numa dinâmica que compreende a participação do intérprete no jogo efetivo e atualizador de sentido da obra. Esta obra de arte tem seu próprio passado (sua origem) vivo em sua atuação no diálogo com o intérprete historicamente formado e que deve, por sua vez, fazer jus à obra e sua mensagem (seus desafios e exigências) e ao seu próprio tempo, sua totalidade de vida. Além disso, parece-nos que, antes de uma postura metodológica frente às obras da cultura, há algo que é anterior nessa experiência. É neste sentido que Grondin nos indaga se “[n]ão seria mais óbvio recorrer à tradição do humanismo, a fim de comprender a pretensão de verdade e o modo de conhecimento das ciências humanas, em vez de partir do paradigma metodológico?”'.

É interessante que esse mesmo questionamento se amplia ao final de Verdade e Método, abarcando não mais apenas as Ciências do Espírito (Geisteswissenschaften), mas também as Ciências da Natureza (Naturwissenschaften). Para tanto, a reabilitação da filosofia prática aristotélica no seio da hermenêutica filosófica tem papel fundamental.

\section{HERMENÊUTICA FILOSÓFICA COMO PRÁXIS: O SENTIDO DO COMPREENDER}

Do contexto da hermenêutica clássica (jurídica e teológica nomeadamente) e moderna (romântica e histórica), Gadamer extrai o problema da relação entre o geral (o texto e seu todo de sentido) e o particular (sua interpretação-aplicação). Suas reflexões até dado ponto de Verdade e Método apontam para o fato de que uma mesma tradição é compreendida a cada tempo de maneira diferente sem que isso constitua perda ou desvirtuação do conteúdo do compreendido. Nesse sentido, “compreender [parece], então, é um caso especial de aplicação de algo universal a uma situação particular"11. Tendo isso em mente, como manter a unidade de sentido daquilo que é legado? Além disso, como explicar essa dinâmica entre compreender o texto ou um discurso oral, sua interpretação, e a aplicação de sorte a que esses momentos não estejam desvinculados, mas que sejam uma só e mesma coisa sempre? Ou seja, que compreender algo

10 GRONDIN, 2003, p. 47. No original: “¿[n]o seria más obvio recurrir a la tradición del humanismo, a fim de comprender la preteción de verdad y el modo de conocimiento de las ciencias humanas, en vez de partir del paradigma metodológico?”.

11 GADAMER, 1996, p. 312. 
sempre implica necessariamente sua interpretação e aplicação. É em Aristóteles que Gadamer busca uma compreensão de tal estado de coisas problemático:

É verdade que Aristóteles não se ocupa com o problema hermenêutico e nem certamente com sua dimensão histórica, mas com a consideração do papel que a razão deve executar na ação moral. Mas o que nos interessa aqui é precisamente que ele está ocupado com a razão e seu saber como não apartada de um ser que está sendo, mas determinada por isto e determinante para isso. Ao circunscrever o intelectualismo de Sócrates e Platão em sua investigação sobre o bem, Aristóteles se tornou o fundador da ética como uma disciplina independente da metafísica. Ao criticar a ideia platônica do bem como uma generalidade vazia, ele se pergunta ao invés pela questão do que é humanamente bom, o que é bom em termos de ação humana ${ }^{12}$.

Daqui tiramos algumas questões pontuais: 1) articular ética e conhecimento (razão); 2) fundamentar uma noção ontológica de aplicação hermenêutica partindo do modo de ser do humano em sua lida prática e de acordo com as lições aristotélicas da consciência moral. Iremos seguir a análise a partir desse esquema de problemas.

Com efeito, no livro I da Ética a Nicômaco, Aristóteles está às voltas de especificar o objeto de estudo de uma ética filosófica, além de determinar os problemas a serem resolvidos e a maneira como se deve levar a cabo tal empreendimento. Nesse sentido, logo definirá o Bem no agir ético humano como aquilo que deve ser perquirido, pois “[t]oda arte e toda investigação, e do mesmo modo todo exercício prático ou empresa, parece apontar para algum bem: consequentemente, foi corretamente dito que o Bem é aquilo a que todas as coisas se direcionam”13. Como é próprio de seu pensamento, Aristóteles tentará fazer jus à especificidade de seu objeto, e nesse caminho reconhecerá que o conhecimento dele extraído não possui a exatidão e imutabilidade própria às ciências teóricas - cujo modelo para os gregos parecia ser a matemática. Porém, por mais que seja essa a situação cognitiva da Ética, ainda assim se trata de uma forma de conhecimento que está em jogo.

12 Idem, p. 312.

13 ARISTOTLE, 1934, p. 3, [1094, I, i, 1-2]. Traduzimos essa passagem da tradução em inglês feita por H. Rackham para a Havard University Press. Adotaremos tal expediente em todas as passagens retiradas dessa edição. 
Segundo Gadamer, trata-se de uma questão eminentemente afeita ao homem, o qual se constitui efetivamente como um ser finito e sujeito ao devir de uma maneira particular. Pois, a partir das reflexões precedentes em Verdade e Método, parece ter restado demonstrado que o ser humano está constantemente em formação de seu ser na medida própria de sua lida com o mundo e com os outros, de maneira que "ele se torna aquilo que é através do que ele faz e de como ele se comporta - i.e., ele se comporta de uma certa maneira por conta daquilo que ele veio a ser"14. O homem trabalha-se a si mesmo, é seu próprio “material bruto” com suas características próprias; mas suas ambições (fins) e modos são ajustados concretamente.

Nesse sentido, uma perplexidade a que a Ética a Nicômaco nos introduz é o fato de que o saber ético não é teórico (no sentido de que é uma doutrina previamente adquirida) e nem pode ser ensinado enquanto tal, ou seja, o mestre não ensina ao aprendiz da moralidade um esquema normativo técnico e/ou conceitual a partir do qual todo o agir poderá se desenvolver lógico demonstrativamente, ou mesmo à maneira da tekhne, a qual compreende um fazer prático que possui uma performance de aplicação de um saber prévio a um fazer particular (a obra a ser realizada), e que ganha maior precisão nesse exercício prático. É inclusive ao pensar essa relação entre tekhne e práxis que Aristóteles ofereceu bons frutos para Gadamer. Em ambos os casos há aplicação de um certo saber à situação dada, e assim também é o modo de proceder da hermenêutica. Todavia, há diferenças de caráter ontológico e procedimental entre as duas primeiras, e a explicitação e reflexão sobre isso lançará luz sobre a especificidade da hermenêutica. Nesse caminho, uma evidência primeira servirá de princípio: a "matéria" da tekhne não está à disposição do mesmo modo como o homem - que é a "matéria" da própria ação moral, na medida em que se trata de decidir sobre seu próprio agir - está para si mesmo na práxis, o que envolve necessariamente um conhecimento diverso. Ou seja, saber como moldar o barro úmido para a fabricação de um vaso não é o mesmo que conhecer a si mesmo para a práxis, ou seja, autocompreender-se. Isso posto, Gadamer nos diz que:

É a distinção do conhecimento técnico que é a tarefa mais difícil se, com Aristóteles, nós definirmos ontologicamente o “objeto” desse conhecimento não como algo geral que sempre é como é, mas como algo individual que pode ser

14 GADAMER, 1996, p. 312. 
também diferente. Pois à primeira vista as tarefas parecem ser totalmente análogas. Uma pessoa que sabe fazer algo sabe algo bom, e ela sabe "por si mesma", de modo que, onde houver a possibilidade de fazê-lo, ele realmente será capaz de realizá-lo. Ele usa o material certo e escolhe os meios corretos para o trabalho. Portanto, ele deve saber como aplicar à situação concreta o que foi aprendido de modo geral. O mesmo não é verdadeiro para a consciência moral? Uma pessoa que deve decidir moralmente sempre já tem algo aprendido. Ele foi tanto formado pela educação e costume, então ele sabe o que é correto em geral. A tarefa de decidir moralmente é aquela que implica fazer a coisa certa numa situação particular - i.e., enxergar o que é correto dentro da situação e apreendê-lo. Ele também deve agir ao escolher os meios adequados, e sua conduta deve ser guiada tão cuidadosamente quanto a do artesão. Como, então, isto é, ainda assim, um conhecimento de um tipo totalmente diferente? ${ }^{15}$

A discussão que se segue a partir daí é extensa para o presente momento, de modo que iremos apresentá-la apenas em seus resultados mais significativos. A primeira intelecção é que o conhecimento moral não se destaca de seu próprio exercício. $\mathrm{Na}$ verdade, seu conteúdo é determinado primordialmente pelo o que a situação exige, mesmo que aí esteja em jogo nosso ser previamente formado. A questão é que no caso de um artesão, por exemplo, mesmo que ele não tenha total domínio sobre aquilo que pode efetivamente acontecer no processo (a madeira pode quebrar, o barro pode ser de má qualidade, talvez algo demore mais do que esperado etc.), ainda assim ele sabe de antemão o que será realizado no fim de tudo e como [mais ou menos] fazê-lo. No caso de nosso agir eticamente, mesmo que tenhamos alguma orientação prévia de justiça etc., não temos qualquer previsão sobre o que efetivamente será realizado, pois apenas o caso nos dirá aquilo que efetivamente devemos realizar - dar resposta.

Além disso, também no que concerne a escolha dos fins e meios a coisa é bem diversa em ambas as práticas. De fato, o conhecimento técnico tem de antemão seus fins (o artesão deseja fabricar um jarro de barro - este é seu fim) e o que resta é a deliberação sobre os meios de realização disso - tanto no caso de já se possuir um conhecimento sobre eles, como no de não se saber em absoluto quais são. Todavia, a situação daquele que deve decidir como agir implica uma dupla deliberação, a qual é necessariamente pautada por aquilo sobre o que se deve decidir. Se assim não fosse, se os fins já estivessem estabelecidos previamente para cada caso concreto, restaria à ética 
apenas ensinar os meios apropriados a cada caso; mas nossa experiência mais comum mostra que isso não é assim. Quando algo ocorre, não dispomos automaticamente de um fim para nossa ação em vista daquilo. É antes preciso discernimento sobre o acontecimento, apreender aquilo que ele nos exige. A partir de então, somos chamados desde esse átimo a deliberar consigo mesmo sobre o que é correto fazer - a finalidade de nossa ação. É só então que procedemos à escolha dos meios, que é também sempre uma deliberação “interna”. Nesses momentos dramáticos, é nossa sabedoria prática (phronesis), enquanto conhecimento de si mesmo, o domínio de nossas capacidades (em sentido lato), que determinará o que se seguirá - e isso não pode ser ensinado teoricamente, mas apenas com experiência prática, exercício que nos capacita cada vez mais ao conhecimento de nós mesmos - autocompreensão. É no confronto com as coisas e com os outros que somos expostos a nós mesmos.

A filosofia prática do estagirita oferece, pois, à hermenêutica uma justificativa não-metodológica e técnica de seu fazer. Também a hermenêutica é práxis, e, enquanto tal, não pode ser ensinada abstratamente em seu proceder. Nossa compreensão ganha amplitude, rigor e profundidade apenas em seu exercício aberto com as coisas. Assim,

[...] se nós relacionarmos à nossa investigação a descrição de Aristóteles do fenômeno ético e, especialmente, a virtude do conhecimento moral, nós descobriremos que suas análises de fato oferecem um certo modelo dos problemas da hermenêutica. Nós também determinamos que aplicação não é nem uma subsequente ou mera parte ocasional do fenômeno da compreensão, mas o codetermina como um todo desde o início. Aqui também aplicação não consistiu em relacionar algum universal previamente dado com a situação particular. O intérprete ao lidar com um texto tradicional tenta aplicá-lo a si mesmo [ao intérprete]. Mas isso não significa que o texto é tido por ele como algo universal, o qual ele primeiramente entende em si mesmo, e então, depois, usa-o ara aplicações particulares. Em vez disso, o intérprete busca não mais do que compreender esse universal, o texto - i.e., compreender o que ele diz, aquilo que constitui o sentido e significado do texto. Para compreender isto, ele não deve descartar a si mesmo e sua situação hermenêutica particular. Ele deve relacionar o texto a essa situação, se desejar compreender alguma coisa ${ }^{16}$.

O que Gadamer parece nos querer ensinar é que, assim como no agir moral, a interpretação de um texto não se dá numa livre e distanciada avaliação, mas que implica

16 GADAMER, 1996, p. 324 
desde antemão um chamado de nosso ser - falando, digamos, mais heideggerianamente. A unidade da tradição e do hermeneuta - tendo-se em vista que todos somos hermeneutas a todo instante - é tal, que o trabalho de um é o do outro e vice e versa. Ao fim e ao cabo, a lição do "primeiro" Heidegger se mostra vigente: hermenêutica da facticidade implica uma via de mão dupla: a interpretação de "si mesmo" já é ser si mesmo sempre. Contudo, no matiz gadameriano se tem, a partir disso, um outro âmbito: compreender o outro é sempre compreender a si mesmo.

\section{BIGLIOGRAFIA CONSULTADA}

ARISTOTLE. The nicomachean ethics. Revised ed. Trad. H. Rackham. Cambridge e Londres: Havard University Press, 1934.

BATISTA, Gustavo Silvano. Hermenêutica e práxis em Gadamer. 2007. 96f. Dissertação (Mestrado em Filosofia). Pontifícia Universidade Católica do Rio de Janeiro, Rio de Janeiro.

DUQUE-ESTRADA, Paulo Cesar. Gadamer's rehabilitation of pratical philosophy: an overview. 1993. 180f. Tese (Doutorado em Filosofia). Boston College, Boston.

GADAMER, Hans-Georg. Hermenêutica em retrospectiva I: Heidegger em retrospectiva. Trad. Marco Antônio Casanova. Petrópolis: Vozes, 2007.

. Truth and Method. 2. ed. Trad. Joel Weisheimer and Donald Marshall. New York: Continuum, 1996.

. Verdad y método. $4^{\mathrm{a}}$ ed. Trad. Ana Agud Aparicio y Rafael de Agapito. Salamanca: Ediciones Sígueme, 1991.

. Verdade e Método. 14. ed. Trad. Flávio Paulo Meurer. Petrópolis: Vozes; Bragança Paulista: Editora Universitária São Francisco, 2014.

. Wahrheit und methode. Tübingen: J.C.B. Mohr, 1960.

GRONDIN, Jean. Introducción a Gadamer. Trad. Constantino Ruiz-Garrido. Barcelona: Herder Editorial, 2003. 
HEIDEGGER, Martin. Basic concepts of Aristotelian philosophy. Trad. Robert D. Metcalf and Mark B. Tanzer. Bloomington e Indianápolis: Indiana University Press, 2009.

_. Grundbegriffe der aristotelischen Philosophie. Frankfurt am Main: Vittorio Klostermann, 2002.

_. Interpretações fenomenológicas sobre Aristóteles. Trad. Ênio Paulo Giachini. Petrópolis, 2011.

_. Ontologia: Hermenêutica da Facticidade. $2^{\mathrm{a}}$ ed. Trad. Renato Kichner. Petrópolis: Vozes, 2013 .

VOLPI, Franco. Heidegger e Aristóteles. Trad. José Trindade dos Santos. São Paulo: Edições Loyola, 2013. 